\title{
Changes in alkaline phosphatase, calcium, C-reactive protein, D-dimer, phosphorus and hemoglobin in elderly osteoporotic hip fracture patients
}

\author{
Zhineng Chen ${ }^{1,2}$, Lili Xie ${ }^{3}$, Jie Xu ${ }^{4}$, Xiaofang Lin ${ }^{1}$, Juncai Ye ${ }^{1,2}$, Rongxue Shao ${ }^{1,5}$, Xinmiao Yao ${ }^{1,2}$ \\ ${ }^{1}$ The Third Clinical Medical College of Zhejiang Chinese Medical University, Hangzhou, Zhejiang, China; ${ }^{2}$ Department of Orthopaedics, The \\ Third Affiliated Hospital of Zhejiang Chinese Medical University, Hangzhou, China; ${ }^{3}$ Department of Gynecology, Traumatology and Orthopedics \\ Hospital of Traditional Chinese Medicine of Xiaoshan District, Hangzhou, China; ${ }^{4}$ Department of Orthopaedics, Traumatology and Orthopedics \\ Hospital of Traditional Chinese Medicine of Xiaoshan District, Hangzhou, China; ${ }^{5}$ Department of Orthopaedics, The Guangxin Affiliated Hospital \\ of Zhejiang Chinese Medical University, Hangzhou, China \\ Contributions: (I) Conception and design: Z Chen, L Xie; (II) Administrative support: X Yao, R Shao, J Xu J; (III) Provision of study materials or \\ patients: X Yao, R Shao, J Xu; (IV) Collection and assembly of data: B He, J Ye; (V) Data analysis and interpretation: B He, J Ye; (VI) Manuscript \\ writing: All authors; (VII) Final approval of manuscript: All authors. \\ Correspondence to: Professor Xinmiao Yao. Department of Orthopedics, The Third Affiliated Hospital of Zhejiang Chinese Medical University, 219 \\ Moganshan Road, Hangzhou, China. Email: yaoxm104@163.com.
}

Background: This study aims to evaluate the association between serum alkaline phosphatase (ALP), calcium (Ca) and phosphorus (P), C-reactive protein (CRP) and D-dimer (D-D), and hemoglobin (Hb) in postoperative and preoperative osteoporotic hip fracture elderly patients.

Methods: A total of 32 operation patients with osteoporotic hip fracture over the age of 65 years old were admitted to the orthopedic unit and prospectively evaluated. All patients were treated according to specific protocols, according to the type of fracture. Fasting blood samples were taken, and serum ALP, Ca and P measurements were respectively performed in six periods: at the time of admission, post-operation, and at postoperative one week, two weeks, one month and three months. Hb, CRP and D-D were also analyzed, and the fracture healing was recorded.

Results: Finally, 32 cases were selected for the present study. The analysis results revealed that the level of serum Ca and ALP slowly increased at two weeks after surgery, and slightly dropped back at three months after the operation. Furthermore, D-D and CRP had a significant effect at pre- and post-operation, and exhibited an obvious downward trend after postoperative one week. The fracture healing and recovery of activities were associated with the Hb levels. The serum levels of ALP, which were adjusted by $\mathrm{Ca}$ and P, were associated with $\mathrm{Hb}$ and CRP, but not with $\mathrm{D}-\mathrm{D}$.

Conclusions: Interestingly, there was an association between CRP and D-D. These findings suggest that early control of inflammation and loss of Ca could play a positive role for the healing of osteoporotic hip fractures.

Keywords: Senile osteoporotic hip fracture; alkaline phosphatase (ALP); calcium (Ca); C-reactive protein (CRP); plasma D-dimer (plasma D-D)

Submitted Jan 17, 2020. Accepted for publication Aug 10, 2020.

doi: 10.21037/apm-20-218

View this article at: http://dx.doi.org/10.21037/apm-20-218 


\section{Introduction}

Osteoporosis is a disease characterized by a decrease in bone amount, with consequent increases in skeletal fragility and heightened risk of fractures, and these occur with minimal trauma. More than 90 million patients have an osteoporosis, and there are more than 170 million elderly people in China. It has been reported that over 250,000 people suffer from hip fractures annually in China (1). Osteoporosis fracture has the most serious consequences. Hip fracture as one of the most serious complications of osteoporosis, which has increasingly become a focus of attention. Due to the high mortality, morbidity and disability rates, hip fracture patients have become a major challenge for the healthcare system, as well as for society (2).

At present, as an effective approach to cure hip fractures, an operation is the accepted method, and its effect has been considered to be superior to that of conservative methods $(3,4)$. A timely surgical management that allows early mobilization is the key in reducing the high inherent mortality following these fractures (5). The treatment of osteoporotic hip fracture depends not only on the antiosteoporosis treatment, but also on the change in internal environment. Bone quality is a very important concept, with respect to osteoporosis hip fractures. It comprehends both bone structure and bone composition, which in turn, includes cells, proteins and mineralization. Calcium $(\mathrm{Ca})$ has an anti-fracture effect based on its key structural role in bone mineralization and metabolic balance $(6,7)$. Serum $\mathrm{Ca}$ levels present some changes in different periods of the fracture healing process (8). The fluctuation of serum $\mathrm{Ca}$ levels may represent the capability of $\mathrm{Ca}$ transportation, reservation, bone metabolism and restoration (9). Studies in older patients have demonstrated the association between chronic anemia and health-related quality of life $(10,11)$. Alkaline phosphatase (ALP) is a marker of bone formation. ALP is widely found in many organs, including liver, kidney and bone. Liver and osteoblasts are the main sources of serum ALP, accounting for about $50 \%$ each $(12,13)$. D-dimer (D-D) is a useful marker to monitor prophylaxis in trauma surgery patients (14). Higher Hb levels at hospital discharge correlated with a positive change of overall quality of life in operated frail elderly hip fracture patients $(15,16)$. Serum C-reactive protein (CRP) levels have been reported to be negatively associated with bone mineral density (BMD) in epidemiologic studies $(17,18)$. Thus, CRP is likely to be linked to bone fragility and fracture risk. The effective treatment of osteoporosis and the fracture itself remains as a major issue. In order to achieve solutions to biomechanical and internal environment problems, the material and structural properties of bone that determine its strength and metabolism must be quantified. A number of pharmacological treatments and clinical interventions have been proposed to reduce osteoclastic bone resorption and increase osteoblastic bone formation, in order to improve quality of life, and thereby prevent the progression of fragility. An appropriate treatment of osteoporosis has been reported to reduce fracture risk from $40 \%$ to $60 \%$ (19). For elderly patients, whose body organs gradually lose function, they are more likely to experience waterelectrolyte and acid-base balance disorders, and serious cases can encounter multiple organ failure. Therefore, it is an important reference value for clinical doctors to determine whether perioperative bone metabolism and the internal environment would significantly change in the body. Therefore, it is crucial to predict the intervention points of osteoporotic hip fractures and/or identify the bone biochemical characteristics of fractures, in order to apply evidence-based pharmacological and non-pharmacological treatment options for prevention. The first objective of the present study was to evaluate the association and change rule between serum levels of alkaline phosphatase (ALP) and $\mathrm{Ca}$ /phosphorus (P), and CRP and D-D, and hemoglobin $(\mathrm{Hb})$ with the bone healing process, while the second objective was to assess the timing of intervention for the osteoporosis after osteoporotic hip fracture. We present the following article in accordance with the STROBE reporting checklist (available at http://dx.doi.org/10.21037/ apm-20-218).

\section{Methods}

\section{Patients and methods}

The present cohort included 32 geriatric osteoporosis patients (21 females and 11 males), who were admitted to our hospital with hip fractures between January 2015 and May 2016. All patients underwent operative treatment by the same doctor. Osteosynthesis was conducted for the trochan-teric fracture using closed traction reduction, and minimally invasive incision proximal femur rotary intramedullary nailing (Weigao, Dabo, China) fixation.

Blood was taken for laboratory tests at a biochemical service laboratory in six periods: at the time of admission, post-operation, and at postoperative one week, two weeks, one month and three months. The serum samples were 


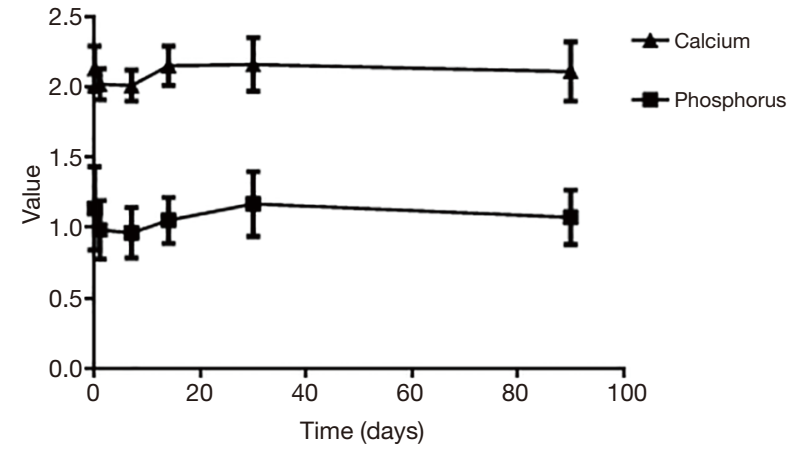

Figure 1 Serum levels of calcium (Ca) and phosphorus (P) according to different stages.

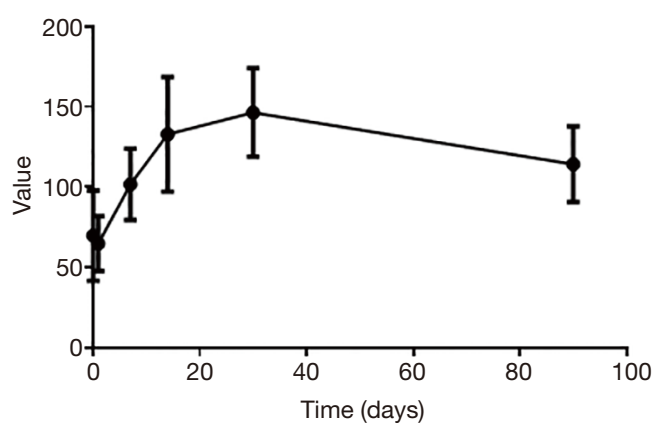

Figure 2 Serum levels of alkaline phosphatase (ALP) according to different stages.

determined for ALP (U/L), Ca (mmol/L), P (mmol/L), D-D $(\mathrm{mg} / \mathrm{L})$, CRP $(\mathrm{mg} / \mathrm{L})$ and $\mathrm{Hb}(\mathrm{mg} / \mathrm{L})$, while the routine biochemical parameters were routinely tested in the same laboratory. ALP level was detected by aminoantipyrine phenolic assay (Kim's method) (USA Beckman Coulter Co., Ltd), and Ca, P levels (USA Beckman Coulter Co., Ltd.) were determined by $\mathrm{O}$-cresolphthalein complex ketone assay. CRP values were measured by Scattering turbidimetry (PA990 quick scanning machine, Guangzhou Guolun Technology Co. LTD). D-D were measured by immunoturbidimetry (Sysmex CS5100, Xiesen Meikang Medical Electronics (Shanghai) Co., LTD). Hb were measured by SLS Hb method [Sysmex B2, Xiesen Meikang Medical Electronics (Shanghai) Co., LTD]. All patients were followed-up during their hospital stay and after discharge, and the fracture healing was recorded. The quality of life was assessed by SF-36. The SF-36 assesses healthrelated quality of life in areas: (I) limitations in physical activities because of health problems; (II) limitations in social activities because of physical or emotional problems;
(III) limitations in usual role activities because of physical health problems; (IV) bodily pain; (V) general mental health (psychological distress and well-being); (VI) limitations in usual role activities because of emotional problems; (VII) vitality (energy and fatigue); and (VIII) general health perceptions (20). The study was conducted in accordance with the Declaration of Helsinki (as revised in 2013). The study was approved by institutional/regional/national ethics/committee/ethics board of The Third Clinical Medical College of Zhejiang Chinese Medical University (No. 2016ZA105) and informed consent was taken from all the patients.

\section{Statistical analysis}

The present data was analyzed by the Statistics Department in our center. The data, which were expressed as mean \pm standard deviation (SD), were analyzed using the SPSS 17.0 software (SPSS Inc., Chicago, Illinois, USA), and statistically significant values were set as $\mathrm{P}<0.05$ and two-tailed. Mean, standard deviation, median, range and percentage were used for descriptive purposes. The univariate correlation at baseline between $\mathrm{Hb}$ and CRP, and between ALP and serum $\mathrm{Ca} / \mathrm{P}$ were analyzed using Pearson's correlation coefficient and Spearman's rank correlation coefficient, respectively. Analysis of variance (ANOVA) was used to compare serum $\mathrm{Ca}, \mathrm{P}, \mathrm{D}-\mathrm{D}, \mathrm{Hb}$, ALP and CRP levels of six different periods. Repeated measures ANOVA was also carried out.

\section{Results}

The age at injury of these patients ranged from 65 to 92 years old (mean: 81.68 years old). The mean time from injury to admission was $36.80 \pm 38.60$ hours, the mean time from admission to surgery was $81.39 \pm 55.36$ hours, and the mean length of surgery was $1.11 \pm 0.27$ hours. Furthermore, the mean time from operation to discharge was $23.33 \pm 18.73$ days. The mean healing time was $3.16 \pm 0.7$ months. The serum Ca, P, D-D, Hb, ALP, CRP and laboratorial data according to the different stages are listed in Figures 1-4. The ANOVA results for the serum Ca and $\mathrm{P}$ revealed that there was a significant effect between pre-operation and post-operation $(\mathrm{P}=0.004,0.006)$, between pre-operation and postoperative one week $(\mathrm{P}=0.002,0.002)$ (Figures 1,5). The level of serum Ca was slowly increased at two weeks after the surgery, and drop back at three months after the operation. The change in blood Ca level and ALP 


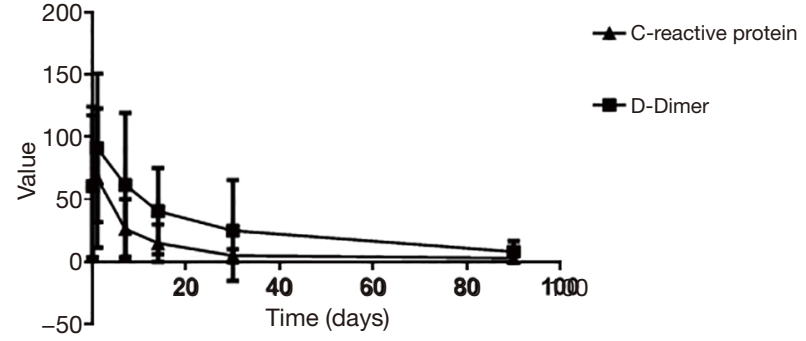

Figure 3 Serum levels of C-reactive protein (CRP) and D-dimer (D-D) according to different stages.

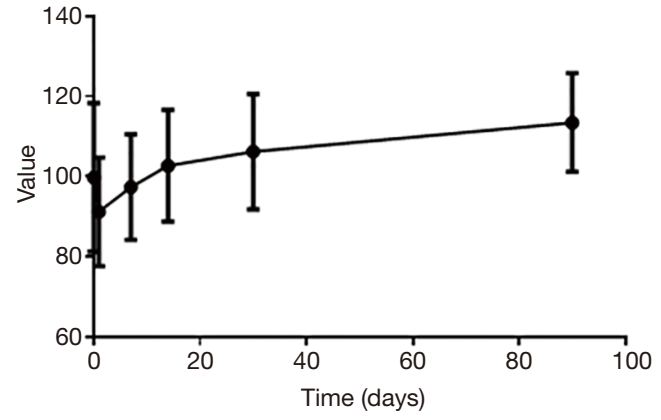

Figure 4 Serum levels of hemoglobin (Hb) according to different stages.

\begin{tabular}{|c|c|c|c|c|c|c|c|c|}
\hline \multicolumn{9}{|c|}{ ANOVA } \\
\hline \multicolumn{4}{|c|}{$\mathrm{Ca}$} & Sum of squares & \multirow{2}{*}{$\frac{d f}{5}$} & Mean square & \multirow{2}{*}{$\frac{F}{5.587}$} & \multirow{2}{*}{$\frac{\text { Sig. }}{0.000}$} \\
\hline \multirow{4}{*}{\multicolumn{2}{|c|}{ Between Groups }} & \multicolumn{2}{|c|}{ (Combined) } & 0.658 & & 0.132 & & \\
\hline & & \multirow{3}{*}{ Linear Term } & Unweighted & 0.081 & 1 & 0.081 & 3.431 & 0.066 \\
\hline & & & Weighted & 0.072 & 1 & 0.072 & 3.074 & 0.081 \\
\hline & & & Deviation & 0.586 & 4 & 0.146 & 6.215 & 0.000 \\
\hline \multicolumn{4}{|c|}{ Within Groups } & 3.864 & 164 & 0.024 & & \\
\hline \multicolumn{4}{|c|}{ Total } & 4.522 & 169 & & & \\
\hline \multicolumn{9}{|c|}{ ANOVA } \\
\hline \multicolumn{4}{|c|}{$\mathrm{P}$} & Sum of squares & $d f$ & Mean square & $\mathrm{F}$ & Sig. \\
\hline \multirow{4}{*}{\multicolumn{2}{|c|}{ Between Groups }} & \multicolumn{2}{|c|}{ (Combined) } & 0.956 & 5 & 0.191 & 4.016 & 0.002 \\
\hline & & \multirow{3}{*}{ Linear Term } & Unweighted & 0.043 & 1 & 0.043 & 0.905 & 0.343 \\
\hline & & & Weighted & 0.028 & 1 & 0.028 & 0.587 & 0.445 \\
\hline & & & Deviation & 0.928 & 4 & 0.232 & 4.873 & 0.001 \\
\hline \multicolumn{4}{|c|}{ Within Groups } & 7.807 & 164 & 0.048 & & \\
\hline \multicolumn{4}{|c|}{ Total } & 8.763 & 169 & & & \\
\hline & & & & & $\mathrm{Ca}$ & & $P$ & \\
\hline & & Pearson & Correlation & & 1 & & 0.292 & \\
\hline $\mathrm{Ca}$ & & Sig. & 2-tailed) & & & & 0.000 & \\
\hline & & & $\mathrm{N}$ & & 170 & & 170 & \\
\hline & & Pearson & Correlation & & 0.292 & & 1 & \\
\hline$P$ & & Sig. & 2-tailed) & & 0.000 & & & \\
\hline & & & $\mathrm{N}$ & & 170 & & 170 & \\
\hline
\end{tabular}

Figure 5 Serum levels of calcium $(\mathrm{Ca})$ and phosphorus $(\mathrm{P})$ for ANOVA according to different stages.

was consistent, but there was no significant meaning at pre-operation and post-operation $(\mathrm{P}=0.446)$ (Figures 2,6). The ANOVA results for the D-D and CRP revealed a significant effect between pre-operation and post-operation $(\mathrm{P}=0.011,0.015)$, and the process gradually declined after postoperative one week (Figures 3,7). The ANOVA results for $\mathrm{Hb}$ revealed a significant effect between pre-operation and post-operation $(\mathrm{P}=0.02)$. The level of serum $\mathrm{Hb}$ slowly increased after postoperative one week (Figures 4,8). In the multiple linear regression analysis with robust standard 


\begin{tabular}{|c|c|c|c|c|c|c|c|}
\hline \multicolumn{8}{|c|}{ ANOVA } \\
\hline \multicolumn{3}{|c|}{ ALP } & Sum of squares & df & Mean square & $\mathrm{F}$ & Sig. \\
\hline \multirow{4}{*}{$\begin{array}{c}\text { Between } \\
\text { Groups }\end{array}$} & \multicolumn{2}{|c|}{ (Combined) } & 152791.280 & 5 & 30558.256 & 45.295 & 0.000 \\
\hline & \multirow{3}{*}{$\begin{array}{l}\text { Linear } \\
\text { Term }\end{array}$} & Unweighted & 97261.455 & 1 & 97261.455 & 144.164 & 0.000 \\
\hline & & Weighted & 103778.194 & 1 & 103778.194 & 153.824 & 0.000 \\
\hline & & Deviation & 49013.086 & 4 & 12253.272 & 18.162 & 0.000 \\
\hline \multicolumn{3}{|c|}{ Within Groups } & 110643.696 & 164 & 674.657 & & \\
\hline \multicolumn{3}{|c|}{ Total } & 263434.976 & 169 & & & \\
\hline
\end{tabular}

\begin{tabular}{|c|c|c|c|}
\hline \multicolumn{4}{|c|}{ Correlations } \\
\hline & & ALP & $\mathrm{Ca}$ \\
\hline \multirow[t]{3}{*}{ ALP } & Pearson Correlation & 1 & $0.195^{*}$ \\
\hline & Sig. (2-tailed) & & 0.011 \\
\hline & $\mathrm{N}$ & 170 & 170 \\
\hline \multirow[t]{3}{*}{$\mathrm{Ca}$} & Pearson Correlation & $0.195^{*}$ & 1 \\
\hline & Sig. (2-tailed) & 0.011 & \\
\hline & $\mathrm{N}$ & 170 & 170 \\
\hline
\end{tabular}

Figure 6 Serum levels of alkaline phosphatase (ALP) and calcium (Ca) for ANOVA according to different stages.

\begin{tabular}{|c|c|c|c|c|c|c|c|}
\hline \multicolumn{8}{|c|}{ ANOVA } \\
\hline \multicolumn{3}{|c|}{ CRP } & Sum of squares & df & Mean square & $\mathrm{F}$ & Sig. \\
\hline \multirow{4}{*}{$\begin{array}{l}\text { Between } \\
\text { Groups }\end{array}$} & \multicolumn{2}{|c|}{ (Combined) } & 117886.697 & 5 & 23577.339 & 16.120 & 0.000 \\
\hline & \multirow{3}{*}{ Linear Term } & Unweighted & 98624.304 & 1 & 98624.304 & 67.429 & 0.000 \\
\hline & & Weighted & 103079.996 & 1 & 103079.996 & 70.475 & 0.000 \\
\hline & & Deviation & 14806.702 & 4 & 3701.675 & 2.531 & 0.043 \\
\hline \multicolumn{3}{|c|}{ Within Groups } & 231096.694 & 158 & 1462.637 & & \\
\hline \multicolumn{3}{|c|}{ Total } & 348983.392 & 163 & & & \\
\hline \multicolumn{8}{|c|}{ ANOVA } \\
\hline \multicolumn{3}{|c|}{ D-dimer } & Sum of squares & $d f$ & Mean square & $\mathrm{F}$ & Sig. \\
\hline \multirow{4}{*}{$\begin{array}{l}\text { Between } \\
\text { Groups }\end{array}$} & \multicolumn{2}{|c|}{ (Combined) } & 1.209E9 & 5 & $2.417 \mathrm{E} 8$ & 10.532 & 0.000 \\
\hline & \multirow{3}{*}{ Linear Term } & Unweighted & 9.083E8 & 1 & 9.083E8 & 39.571 & 0.000 \\
\hline & & Weighted & 8.718E8 & 1 & 8.718E8 & 37.981 & 0.000 \\
\hline & & Deviation & 3.369E8 & 4 & $8.422 \mathrm{E} 7$ & 3.669 & 0.007 \\
\hline \multicolumn{3}{|c|}{ Within Groups } & 3.627E9 & 158 & $2.295 \mathrm{E} 7$ & & \\
\hline \multicolumn{3}{|c|}{ Total } & 4.836E9 & 163 & & & \\
\hline & & & & & CRP & \multicolumn{2}{|c|}{ Ddimer } \\
\hline \multirow{3}{*}{ CRP } & \multicolumn{3}{|c|}{ Pearson Correlation } & & 1 & 0.325 & \\
\hline & \multicolumn{3}{|c|}{ Sig. (2-tailed) } & & & \multicolumn{2}{|c|}{0.000} \\
\hline & \multicolumn{3}{|c|}{$\mathrm{N}$} & & 164 & \multicolumn{2}{|c|}{164} \\
\hline \multirow{3}{*}{ D dimer } & \multicolumn{3}{|c|}{ Pearson Correlation } & & $0.325^{\star \star}$ & \multicolumn{2}{|l|}{1} \\
\hline & \multicolumn{3}{|c|}{ Sig. (2-tailed) } & & 0.000 & & \\
\hline & \multicolumn{3}{|c|}{$\mathrm{N}$} & & 164 & \multicolumn{2}{|c|}{164} \\
\hline
\end{tabular}

Figure 7 Serum levels of C-reactive protein (CRP) and D-dimer (D-D) for ANOVA according to different stages.

error, the serum levels of ALP adjusted by $\mathrm{Ca}$ and $\mathrm{P}$ were associated with $\mathrm{Hb}$ and CRP, but not with $\mathrm{D}-\mathrm{D}$. The Paired Samples Statistics results for $\mathrm{Hb}$ and SF-36 (physiological function) revealed that $\mathrm{Hb}$ level was positively correlated with physiological function (Figure 9).

\section{Discussion}

The aim of the present study was to evaluate the association between serum levels of ALP with Ca, P, CRP, Hb and D-D after hip fracture. The serum levels of ALP were positively correlated with $\mathrm{Ca}$ and $\mathrm{P}$ in these patients. Interestingly, 


\begin{tabular}{|c|c|c|c|c|c|c|c|}
\hline \multicolumn{8}{|c|}{ ANOVA } \\
\hline \multicolumn{3}{|c|}{$\mathrm{Hb}$} & Sum of squares & df & Mean square & $\mathrm{F}$ & Sig. \\
\hline \multicolumn{3}{|c|}{ (Combined) } & 7906.686 & 5 & 1581.337 & 7.400 & 0.000 \\
\hline \multirow{3}{*}{$\begin{array}{c}\text { Between } \\
\text { Groups }\end{array}$} & \multirow{3}{*}{ Linear Term } & Unweighted & 5520.275 & 1 & 5520.275 & 25.832 & 0.000 \\
\hline & & Weighted & 5151.443 & 1 & 5151.443 & 24.106 & 0.000 \\
\hline & & Deviation & 2755.243 & 4 & 688.811 & 3.223 & 0.014 \\
\hline \multicolumn{3}{|c|}{ Within Groups } & 33765.088 & 158 & 213.703 & & \\
\hline \multicolumn{3}{|c|}{ Total } & 41671.774 & 163 & & & \\
\hline
\end{tabular}

Figure 8 Serum levels of hemoglobin $(\mathrm{Hb})$ for ANOVA according to different stages.

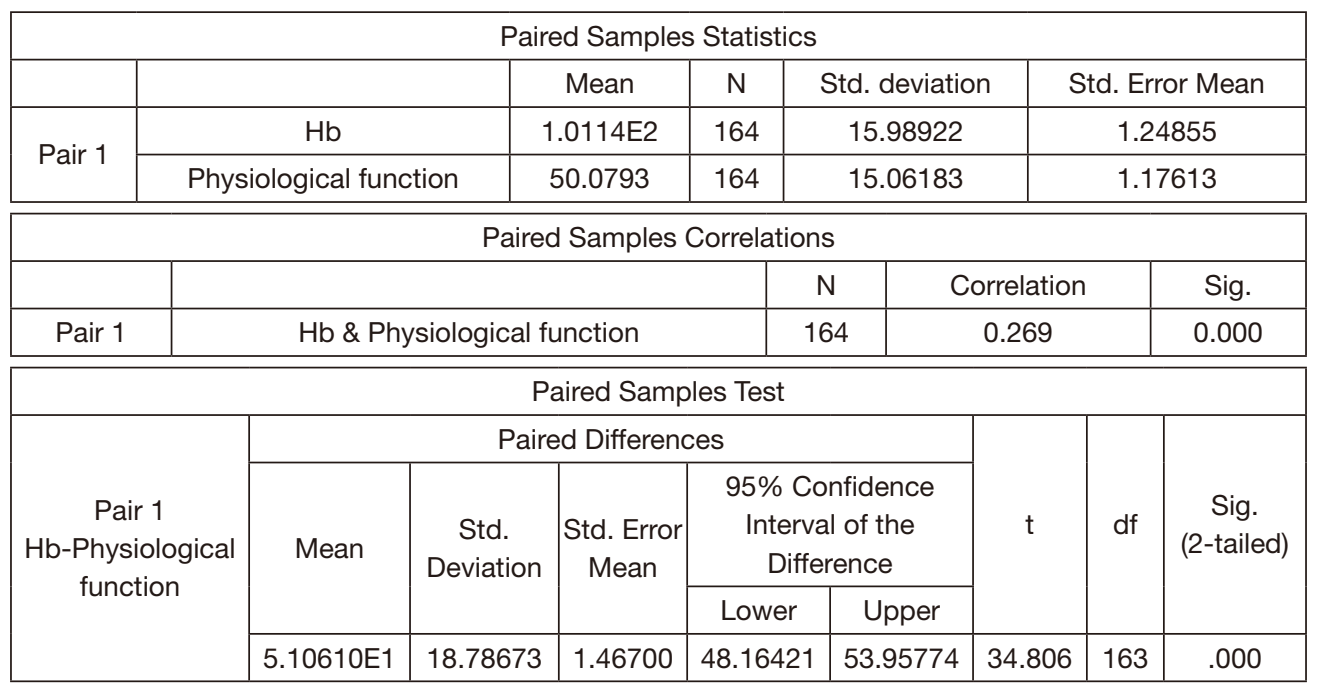

Figure 9 Serum levels of hemoglobin $(\mathrm{Hb})$ and physiological function for Paired Samples Test according to different stages.

there was an association between CRP and D-D. These above mentioned results indicate that promoting bone formation and inhibiting bone absorption, and improving the physical condition should be implemented as early as possible for elderly patients undergoing hip fracture surgery. Osteoporotic hip fracture is a complex fracture that involves many factors $(21,22)$. Osteoporosis fracture is one of the most serious consequences for osteoporosis. Hip fracture and its surgery can significantly increase the serum inflammatory indicators, and excessive inflammatory response may cause the patient's immune exhaustion, resulting in no stress or stress weakness of the body to external antigens (bacteria, etc.), which is not only prone to infection, but also excessive inflammatory response will lead to excessive bone resorption $(23,24)$. Early prevention, timely monitoring, effective anti-osteoporosis and inhibition of excessive inflammatory response during surgical treatment can improve the success rate of fracture treatment and control or reduce the incidence of re-fracture after treatment of osteoporotic fracture. A strategy to secure an adequate and standardized perioperative treatment is important. In particular, there are three clinically relevant indications for utilizing blood biochemical indexes in older osteoporotic hip fracture populations, and monitoring response to therapy: (I) assessment of the physical condition; (II) assessment of the overall secondary fracture risk; (III) the monitoring of the response to therapy.

Elderly patients appear to be less satisfied with life after hip fracture surgery, which produces a substantial negative effect on their quality of life (22). Malnutrition is an important feature of elderly hip fracture patients, and nutritional status has a significant impact on the response of the body skeleton to trauma. Therefore, poor muscle mass and imbalances are important determinants of the decline of organ functions in elderly hip fracture patients. is common after hip fracture surgery (25), 
while chronic anemia is prevalent in older patients due to their frailty and comorbidities. The elderly are prone to the occurrence of trochanteric fractures, and patients with trochanteric fractures due to the situation a person who loses blood is more likely to become anaemic (26). Studies have demonstrated a positive correlation between $\mathrm{Hb}$ levels and quality of life score changes from preoperation to two months after surgery $(10,11,27)$. Some similar associations between $\mathrm{Hb}$ levels and quality of life score changes were also found (28). The loss of blood was associated with medical complications and increased length of hospitalization. In this study, we also found that patients with less $\mathrm{Hb}$ loss had a higher quality of life. At the same time, it was found that fracture healing and the recovery of activities were associated with $\mathrm{Hb}$ levels in the present study. Therefore, there is vital significance to improve the anemia status as early as possible for osteoporotic hip fracture patients at post-operative recovery.

Osteoporotic fractures healing is a complex physiological process that involves a well-orchestrated series of biological events, including inflammation, intramembranous ossification, chondrogenesis, endochondral ossification, and remodeling (29). Bone turnover is accelerated in the elderly, and is associated with bone loss. Alkaline phosphatase is an indicator of bone formation. Intertrochanteric fracture blood supply abundant, active callus formation stages begin early after fracture. Previous studies have also suggested that bone resorption increases early in the fracture (30), and bone formation increased in later stages (31).

Chronic Ca deficiency in the elderly is a major risk factor for osteoporotic fractures (32). Ca deficiency could lead to an increase in Ca mobilization from bone stores, and also result in the suppression of bone formation (33). $\mathrm{P}$ deficiency affects calcification of bone tissue, general weakness, weight loss, bone pain, Osteomalacia and joint rigidity can lead to osteoporosis. There is probably no single cause for accelerated bone resorption in the elderly (34). During these Ca deficiency states, bone formation is suppressed it sure try the best to ensure the supply of $\mathrm{Ca}$ in the circulation. Older individuals are likely to be in a chronic and persistent $\mathrm{Ca}$ deficiency status. Bone turnover is markedly altered in the elderly when dietary $\mathrm{Ca}$ is limited. Clearly, bone resorption is increased by $\mathrm{Ca}$ deficiency, but at the same time, bone formation may also be suppressed. The present study revealed that post-operative $\mathrm{Ca}$ level is in line with the changes in ALP. These Ca and ALP levels tend to be stable as soon as fracture healing occurs. These findings suggest that $\mathrm{Ca}$ supplementation is effective, because it can indirectly block bone resorption. However, it remains unclear what threshold dose of $\mathrm{Ca}$ is required to suppress bone resorption. These findings further suggest that the absorption and utilization of Ca should be promoted as early as possible, since this plays a necessary role for the healing of osteoporotic hip fractures. Biochemical indicators of bone metabolism can reflect fracture healing during bone transition state (35).

Serum CRP is an acute phase reactant and marker of general systemic inflammation. Chronic inflammation may lead to increased bone loss and fragility fractures (36). Inflammatory cytokines are associated with increased bone resorption and decreased bone formation (37). Serum CRP levels have been reported to be negatively associated with BMD $(12,13,38,39)$. Similar to these present findings, previous cohort studies have reported the positive association between serum CRP levels and fracture risk $(40,41)$. These present findings indicate that participants with high CRP levels at pre-operation were more likely to develop osteoporosis, even after accounting for fragility fractures and potential confounding factors on fracture healing $(37,38)$. Serum CRP levels have been found to be negatively associated with ALP in the present study. However, the serum levels of CRP were positively correlated with D-D in these patients. Hence, the quality of life score changes. These findings suggest that the early control inflammation plays a positive role, not only to promote bone formation and inhibit bone absorption, but also to improve the state of blood and reduce thrombosis.

In conclusion, the present study demonstrated that the serum levels of ALP were positively associated with Ca and $\mathrm{P}$ in these patients. It was also confirmed that CRP is correlated with D-D. Furthermore, Hb levels were associated with the subsequent quality of life score changes at post-operation in osteoporosis hip fracture patients. The number of patients enrolled in this study was small, further research should include additional samples and more subgroups of participant follow-ups, bone turnover biomarkers, intervening measures, longer follow-ups, and so on. Future studies are warranted to quantify the serum levels of bone turnover biomarkers, in order to optimize the bone remodeling process for the timing prediction of osteoporosis hip fractures, and evaluate the timing of intervention for anti-osteoporosis treatment after the occurrence of osteoporotic hip fractures.

\section{Acknowledgments}

We would like to thank all of the consultants in the 
Department of Orthopadedics and Image, The Third Affiliated Hospital of Zhejiang Chinese Medical University and Traumatology and Orthopedics Hospital of Traditional Chinese Medicine of Xiaoshan District, Hangzhou, Zhejiang Province in China for agreeing to allow their patients to be involved in this study. We would also like to thank Dr. Xinmiao Yao, Rongxue Shao and Jie Xu for technological instruction in this study. We would also like to thank Bangjiang He and Juncai Ye for with cases collected and statistics; and Lili Xie for research and protocol design. Funding: This study was supported by the science and technology Traditional Chinese Medicine Plan of Zhejiang Province, China (No. 2016ZA105), major disease prevention and control of a public relations program of Chinese medicine of Zhejiang Province, China (No. 2012ZCG004) and key project of natural science foundation of Zhejiang Province, China (No. LZ15H270001).

\section{Footnote}

Reporting Checklist: The authors have completed the STROBE reporting checklist. Available at http://dx.doi. org/10.21037/apm-20-218

Data Sharing Statement: Available at http://dx.doi. org/10.21037/apm-20-218

Conflicts of Interest: All authors have completed the ICMJE uniform disclosure form (available at http://dx.doi. org/10.21037/apm-20-218). The authors have no conflicts of interest to declare.

Ethical Statement: The authors are accountable for all aspects of the work in ensuring that questions related to the accuracy or integrity of any part of the work are appropriately investigated and resolved. The study was conducted in accordance with the Declaration of Helsinki (as revised in 2013). The study was approved by institutional/ regional/national ethics/committee/ethics board of The Third Clinical Medical College of Zhejiang Chinese Medical University (No.2016ZA105) and informed consent was taken from all the patients.

Open Access Statement: This is an Open Access article distributed in accordance with the Creative Commons Attribution-NonCommercial-NoDerivs 4.0 International License (CC BY-NC-ND 4.0), which permits the noncommercial replication and distribution of the article with the strict proviso that no changes or edits are made and the original work is properly cited (including links to both the formal publication through the relevant DOI and the license). See: https://creativecommons.org/licenses/by-nc$\mathrm{nd} / 4.0 /$.

\section{References}

1. Cummings SR, Melton LJ. Epidemiology and outcomes of osteoporotic fractures. Lancet 2002;359:1761-7.

2. Valizadeh M, Mazloomzadeh S, Golmohammadi S, et al. Mortality after low trauma hip fracture: a prospective cohort study. BMC Musculoskelet Disord 2012;13:143.

3. Rodriguez-Fernandez P, Adarraga-Cansino D, Carpintero P. Effects of delayed hip fracture surgery on mortality and morbidity in elderly patients. Clin Orthop Relat Res 2011;469:3218-21.

4. Soucanye de Landevoisin E, Bertani A, Candoni P, et al. Proximal femoral nail antirotation (PFV-ATM) fixation of extra-capsular proximal femoral fractures in the elderly: retrospective study in 102 patients. Orthop Traumatol Surg Res 2012;98:288-95.

5. Pountos I, Giannoudis PV. The management of intertrochanteric hip fractures. Orthopaedics and Trauma 2016;30:103-8.

6. Reid IR, Bolland MJ, Grey A. Effect of calcium supplementation on hip fractures. Osteoporos Int 2008;19:1119-23.

7. Oppl B, Michitsch G, Misof B, et al. Low bone mineral density and fragility fractures in permanent vegetative state patients. J Bone Miner Res 2014;29:1096-100.

8. Li PF, Lin ZL, Pang ZH, et al. Does serum calcium relate to different types of hip fracture? A retrospective study. Chinese Journal of Traumatology 2016;19:275-7.

9. Peacock M. Calcium metabolism in health and disease. Clin J Am Soc Nephrol 2010;5:S23-30.

10. Lucca U, Tettamanti M, Mosconi P, et al. Association of mild anemia with cognitive, functional, mood and quality of life outcomes in the elderly: The "health and anemia" study. PLoS One 2008;3:e1920.

11. Thein M, William B, Artz AS, et al. Diminished quality of life and physical function in community-dwelling elderly with anemia. Medicine 2009;88:107-14.

12. Pan J, Hu HT, Zhang W, et al. Value of Serum Alkaline Phosphatase for Predicting 2-year Fracture in Patients With Chronic Kidney Disease on Dialysis. Nan Fang Yi Ke Da Xue Xue Bao 2018;38:1095-9. 
13. Zhao D, Wang JS, Liu YN, et al. Expressions and Clinical Significance of Serum Bone Gla-protein, Bone Alkaline Phosphatase and C-terminal Telopeptide of Type I Collagen in Bone Metabolism of Patients With Osteoporosis. Pak J Med Sci 2015;31:91-4.

14. Liu LT, Ma BT. Prophylaxis Against Venous Thromboembolism in Orthopedic Surgery. Chin J Traumatol 2006;9:249-56.

15. Gregersen M, Borris LC, Damsgaard EM. Blood Transfusion and Overall Quality of Life After Hip Fracture in Frail Elderly Patients--The Transfusion Requirements in Frail Elderly Randomized Controlled Trial. J Am Med Dir Assoc 2015;16:762-6.

16. Conlon NP, Bale EP, Herbison GP, et al. Postoperative anemia and quality of life after primary hip arthroplasty in patients over 65 years old. Anesthesia Analgesia 2008;106:1056-61.

17. de Pablo P, Cooper MS, Buckley CD. Association between bone mineral density and C-reactive protein in a large population-based sample. Arthritis Rheum 2012;64:2624-31.

18. Ding C, Parameswaran V, Udayan R, et al. Circulating levels of inflammatory markers predict change in bone mineral density and resorption in older adults: a longitudinal study. J Clin Endocrinol Metab 2008;93:1952-8.

19. Aghamirsalim M, Mehrpour SR, Kamrani RS, et al. Effectiveness of educational intervention on undermanagement of osteoporosis in fragility fractures. Arch Orthop Trauma Surg 2012;132:1461-5.

20. Ware JE Jr, Sherbourne CD. The MOS 36-item shortform health survey (SF-36). I. Conceptual framework and item selection. Med Care 1992;30:473-83.

21. Chen YJ, Kung PT, Wang YH, et al. Greater risk of hip fracture in hemodialysis than in peritoneal dialysis. Osteoporos Int 2014;25:1513-8.

22. Ortiz-Alonso FJ, Vidan-Astiz M, Alonso-Armesto M, et al. The pattern of recovery of ambulation after hip fracture differs with age in elderly patients. J Gerontol A Biol Sci Med Sci 2012;67:690-7.

23. Dahl K, Ahmed LA, Joakimsen RM, et al. High-sensitivity C-reactive protein is an independent risk factor for nonvertebral fractures in women and men: The Tromsø Study. Bone 2015;72:65-70.

24. Ahmadi-Abhari S, Luben RN, Wareham NJ, et al. C-reactive protein and fracture risk: European prospective investigation into Cancer Norfolk Study. Bone 2013;56:67-72.
25. Foss NB, Kehlet H. Hidden blood loss after surgery for hip fracture. J Bone Joint Surg Br 2006;88:1053-9.

26. Smith GH, Tsang J, Molyneux SG, et al. The hidden blood loss after hip fracture. Injury 2011;42:133-5.

27. Conlon NP, Bale EP, Herbison GP, et al. Postoperative anemia and health-related quality of life after primary hip arthroplasty in patients over 65 years old. Anesthesia Analgesia 2008;106:1056-61.

28. Gregersen M, Borris L, Damsgaard EM. Postoperative blood transfusion strategy in frail anemic elderly with hip fracture: The TRIFE randomized controlled trial. Acta Orthop 2015;86:363-72.

29. Waki T, Lee SY, Niikura T, et al. Profiling microRNA expression during fracture healing. BMC Musculoskelet Disord 2016;17:83.

30. Sato Y, Kaji M, Higuchi F, et al. Changes in bone and calcium metabolism following hip fracture in elderly patients. Osteoporos Int 2001;12:445-9.

31. Ohishi T, Takahashi M, Kushida K, et al. Changes of biochemical markers during fracture healing. Arch Orthop Trauma Surg 1998;118:126-30.

32. Recker RR, Hinders S, Davies KM, et al. Correcting calcium nutritional deficiency prevents spine fractures in elderly women. J Bone Miner Res 1996;11:1961-6.

33. Prince RL. Diet and the prevention of osteoporotic fractures. N Engl J Med 1997;337:701-2.

34. Dresner-Pollak R, Parker RA, Poku M, et al. Biochemical markers of bone turnover reflect femoral bone loss in elderly women. Calcif Tissue Int 1996;59:328-33.

35. Sousa CP, Dias IR, Lopez-Peña M, et al. Bone turnover markers for early detection of fracture healing disturbances: A review of the scientific literature. An Acad Bras Cienc 2015;87:1049-61.

36. Oei L, Campos-Obando N, Dehghan A, et al. Dissecting the relationship between high-sensitivity serum C-reactive protein and increased fracture risk: the Rotterdam Study. Osteoporos Int 2014;25:1247-54.

37. Lacativa PG, Farias ML. Osteoporosis and inflammation. Arq Bras Endocrinol Metabol2010;54:123-32.

38. Lencel P, Magne D. Inflammaging: the driving force in osteoporosis? Med Hypotheses 2011;76:317-21.

39. Koh JM, Khang YH, Jung CH, et al. Higher circulating hsCRP levels are associated with lower bone mineral density in healthy pre-and postmenopausal women: evidence for a link between systemic inflammation and osteoporosis. Osteoporos Int 2005;16:1263-71.

40. Cauley JA, Danielson ME, Boudreau RM, et al; Health ABC Study. Inflammatory markers and incident 
fracture risk in older men and women: the Health Aging and Body Composition Study. J Bone Miner Res 2007;22:1088-95.

41. Nakamura K, Saito T, Kobayashi R, et al. C-reactive protein predicts incident fracture in community-dwelling elderly Japanese women: the Muramatsu study. Osteoporos Int 2011;22:2145-50.

Cite this article as: Chen $\mathrm{Z}, \mathrm{Xie} \mathrm{L}, \mathrm{Xu} \mathrm{J}$, Lin X, Ye J, Shao R, Yao X. Changes in alkaline phosphatase, calcium, C-reactive protein, D-dimer, phosphorus and hemoglobin in elderly osteoporotic hip fracture patients. Ann Palliat Med 2021;10(2):1079-1088. doi: 10.21037/apm-20-218 